https://helda.helsinki.fi

\title{
Immobility
}

\section{Olkkola, K.T.}

Cambridge University Press

2020

Olkkola , K T \& Eleveld, D J 2020 , Immobility . in P L Gambús \& J F A Hendrickx (eds), Personalized Anaesthesia : Targeting Physiological Systems for Optimal Effect . , 11 , Cambridge University Press , pp. 157-174 . https://doi.org/10.1017/9781316443217.011

http://hdl.handle.net/10138/328587

https://doi.org/10.1017/9781316443217.011

acceptedVersion

Downloaded from Helda, University of Helsinki institutional repository.

This is an electronic reprint of the original article.

This reprint may differ from the original in pagination and typographic detail.

Please cite the original version. 


\title{
Immobility
}

\author{
Klaus T Olkkola ${ }^{1}$ and Douglas J Eleveld ${ }^{2}$ \\ ${ }^{1}$ Department of Anaesthesiology, Intensive Care and Pain Medicine \\ University of Helsinki and Helsinki University Hospital \\ Helsinki, Finland \\ E-mail: klaus.olkkola@helsinki.fi
}

${ }^{2}$ Department of Anaesthesiology

University Medical Center Groningen

University of Groningen

Groningen, The Netherlands

E-mail: d.j.eleveld@umcg.nl

\section{Muscle relaxation and neuromuscular block}

Surgical anaesthesia usually requires hypnosis, antinociception (ensuring blood pressure and heart rate control) and immobility with varying degrees of muscle relaxation. However, the relative contribution of these three components to the state of anaesthesia may vary between different anaesthesias and surgical procedures. While volatile anaesthetics may be used to produce anaesthesia in and by themselves, most often anaesthesia is produced by a combination of drugs. Anaesthesia produced by the concomitant use of hypnotics, analgesics and neuromuscular blocking drugs is called "balanced anaesthesia".

The degree of neuromuscular block induced by neuromuscular blocking drugs and the depth of anaesthesia (induced by other drugs) both affect muscle relaxation ${ }^{[1]}$. While in the early days of our profession deep ether anaesthesia alone provided sufficient muscle relaxation for many procedures, the introduction of neuromuscular blocking drugs nowadays allows us to specifically target specific degrees of muscle relaxation in an easy and safe manner. Provided the airway is secured and adequate ventilation and hypnosis are ensured, adverse effects of neuromuscular blocking drugs are few.

After briefly reviewing pertinent physiology, the different degrees of neuromuscular block depth are defined and the tools to measure them are described. The chapter then focuses on the properties of modern neuromuscular blocking drugs (only cisatracurium, mivacurium, and rocuronium will be discussed) and suxamethonium. Finally, the clinically optimal neuromuscular block is defined, and the different routes to achieve this goal are explored.

\section{Neuromuscular junction}

An action potential causes synaptic vesicles of the motor nerve endings containing the neurotransmitter acetylcholine to fuse with the plasma membrane and release their content into the neuromuscular junction. Acetylcholine then binds to postjunctional nicotinic acetylcholine receptors on the motor endplate. These receptors consist of two alpha and one beta, delta and epsilon subunits. They are directly linked to ion channels. If acetylcholine is bound to both alpha 
subunits, the permeability of the ion channel for $\mathrm{Na}^{+}$and $\mathrm{K}^{+}$ions increases, depolarizing the muscle cell ${ }^{[2]}$. Subsequent calcium release causes contraction of the cell, and if a sufficient number of muscle cells are depolarized simultaneously, muscle contraction ensues.

In addition to the postjunctional receptors, there are also prejunctional acetylcholine receptors that are involved in the modulation of acetylcholine release in the neuromuscular junction. They consist of three alpha and two beta subunits. While clinically used non-depolarizing neuromuscular blocking drugs have affinity for these presynaptic receptors, the only available depolarizing neuromuscular blocking drug, suxamethonium, has not ${ }^{[3]}$. Because a non-depolarizing neuromuscular block displays fade after train of four stimulation (see further) while a suxamethonium induced neuromuscular block does not, it is plausible to explain this by the aforementioned different effects on presynaptic nicotinic acetylcholine receptors. Fade is used to quantify the degree of neuromuscular block elicited by the non-depolarizing neuromuscular blocking drugs.

\section{Quantification of neuromuscular block}

Because the individual response to neuromuscular blocking drugs varies to such an extent that it becomes unpredictable in the individual patient, neuromuscular function has to be measured continually during anaesthesia. Fortunately, of all components making up anaesthesia, the degree of the neuromuscular block is the one that can be quantified most easily by applying a supramaximal electrical stimulus to a peripheral motor nerve and quantifying the subsequent muscle contraction (or other muscle response). A complete or partial neuromuscular block is said to exist if no or some (but not a full) response is present, respectively.

After administration of a neuromuscular blocking drug, the degree of neuromuscular block is not uniform in all muscles throughout the body. For example, laryngeal muscles achieve peak effect faster than peripheral muscles but the effect there also dissipates faster. Both pharmacokinetic (e.g. blood flow) and pharmacodynamic (sensitivity) factors account for these differences. These differences have to be taken into account when monitoring neuromuscular block in one muscle (because ease of access, e.g.) to get an idea of the neuromuscular block in another muscle that may be the more relevant one to ensure optimal surgical conditions - it explains why the quantification of neuromuscular block at hand is not perfectly informative for neuromuscular block at diaphragm or abdominal wall[ ${ }^{[4]}$.

\section{Stimulation patterns}

While quantifying the muscle response following electrical stimulation of a motor nerve seems rather straightforward, in reality it is a rather complex subject.

While a number of stimulation patterns are in widespread use, the type of electrical stimulation is often quite similar. Typically, a unipolar constant-current pulse is used, and this current has to be strong enough to evoke a supramaximal response from the muscle. The reason for the need of supramaximal stimulation is to ensure that the magnitude of muscle contraction is independent of the intensity of the electrical stimulation. If all of the motor units innervated by the stimulated nerve are recruited, then we have supramaximal stimulation. The magnitude of the contraction then (ideally) becomes independent of the magnitude of the electrical stimulus. Under these conditions, the only limiting factor in muscle contraction is the neuromuscular transmission, which is the characteristic of interest. This method also reduces the dependence of muscle contraction on stimulating electrode conditions which can vary during the surgical procedure. Moisture or gel under the electrodes changes the electrical properties of the skin under the electrodes. Typically, 
constant-current pulses of up to 50-60 milliamperes are used with duration of 200-300

microseconds.

Ideally, both the stimulation site (= site where electrodes are placed) and the monitoring site (= site where muscle response is registered) have to remain easily accessible throughout the surgical procedure. Because during most surgical procedures at least one hand is accessible, the ulnar nerve at the wrist and the adductor pollicis it innervates are the most commonly used monitoring sites. When this site is not accessible, the orbicularis oculi or corrugator supercilii at the eye, and the flexor hallucis brevis at the foot can be used. Accessibility of the area of the motor nerve is important for the initial electrode placement, but once the electrodes are placed, often the site does not need repeated access.

Single-twitch stimulation

Single-twitch stimulation refers to the application of a single electrical pulse to a motor nerve, with quantification of the resulting muscle contraction called "single-twitch-response". Before the administration of neuromuscular blocking drugs, a "control twitch" is determined that serves as the baseline muscle contraction to which subsequent twitches are referenced. A value of $0 \%$ indicates complete neuromuscular block, and $100 \%$ indicates no neuromuscular block. While single-twitch stimulation has been used extensively in older research, it has only been rarely applied in routine clinical practice. A proper understanding of this method helps the clinician to gain insight into much of the research on neuromuscular blocking drugs.

The interpretation of the single-twitch stimulation response is confounded by "twitch potentiation", a physiological phenomenon whereby repetitive stimulation can cause a gradual increase in twitch response that ultimately plateaus. To make matters even more complex, the magnitude of the control twitch response may also depend on the stimulation pattern. Because intra-operative neuromuscular transmission monitoring requires repetitive stimulation of the nerve, post-relaxation twitch responses (= responses during and after the recovery of neuromuscular block) will be potentiated and plateau at some higher value. If insufficient time is taken for twitch response stabilization prior to the administration of neuromuscular blocking drugs, twitch potentiation during and after recovery of a drug-induced neuromuscular block can result in a twitch response that exceeds the control twitch (obtained prior to the administration of neuromuscular blocking drugs) by $150-180 \%$. In these conditions, a twitch response of $100 \%$ of the control twitch will falsely indicate full recovery and underestimate a residual block that may still cause the patient to experience clinical signs of residual neuromuscular block.

"Pre-relaxation twitch stabilization" will eliminate "twitch potentiation" as a confounding factor when interpreting twitch responses after the administration of neuromuscular blocking drugs, but reaching a plateau can require up to $30 \mathrm{~min}$ of $0.1-\mathrm{Hz}$ single-twitch simulation. Increasing the stimulation frequency can speed up the rate at which a plateau is reached but may also affect the ultimate plateau height as well. Careful balancing of these effects can be helpful in achieving a stable "control" twitch response before the administration of neuromuscular blocking drugs. A 2second $50-\mathrm{Hz}$ tetanic stimulus followed by 2 minutes of $0.1-\mathrm{Hz}$ stimulus has been suggested to reasonably rapid twitch stabilization ${ }^{[5,6]}$. Some researchers create a mathematical model of the postsynaptic process that causes a rise towards a plateau and incorporate it in their models of muscle relaxation $^{[7]}$.

Train-of-four stimulation pattern

The difficulties of obtaining and interpreting the "control-twitch" for single-twitch stimulation have led to the development of the train-of-four (TOF) stimulation pattern. This stimulation 
pattern consists of 4 electrical pulses separated by 0.5 seconds, with each train usually separated by 12-20 seconds. As the depth of a non-depolarizing neuromuscular block increases, the fourth twitch will diminish first because the previous 3 stimuli have depleted the acetylcholine content of the presynaptic vesicles, causing a preponderance of the competitive inhibitor at the neuromuscular junction. As the concentration of the competitive inhibitor (= non-depolarizing neuromuscular blocking drug) further increases and the block deepens, the third, second and first twitch responses also decrease (in that sequence, because less and less acetylcholine is available during each subsequent pulse in the train-of-four sequence). The origin of the TOF "fade" is thought to be a prejunctional effect of non-depolarizing neuromuscular blocking drugs.

The TOF stimulation pattern eliminates the need for a pre-relaxation control twitch because it references the magnitude of the fourth to the first twitch and uses this ratio to quantify the depth of a neuromuscular block. This ratio is known as the TOF ratio. A TOF ratio of $100 \%$ indicates the absence of neuromuscular block and $0 \%$ indicates that the fourth twitch has disappeared, suggesting a moderately deep level of neuromuscular block. At deeper levels, the third, second and first twitches become progressively smaller and ultimately disappear. As recovery from neuromuscular block occurs, the twitches reappear in order and when the fourth twitch reappears the TOF ratio can be again calculated. Even with a TOF ratio of 1, a significant number of acetylcholine receptors may be blocked. It reflects the considerable margin of safety of neuromuscular transmission: up to $80 \%$ of receptors may be blocked without a noticeable effect on muscle strength. It also explains why the top-up dose of a neuromuscular blocking drug to maintain a certain block is only a fraction of the initial dose (see further).

When the fourth twitch disappears and the so-called TOF count becomes 3 (out of 4 ) and the TOF ratio becomes $0 \%$; a "moderately deep" block is said to exist. Once the TOF ratio becomes 0 , the ratio itself cannot be used to quantify deeper blocks, and the clinician reverts to counting the number of detectable twitch responses after TOF stimulation, with a TOF count of $3,2,1$, and 0 indicating a progressively deeper block. A TOF-count of 0 or 1 corresponds to moderately deep neuromuscular block and indicates that considerable time must elapse before the fourth twitch will reappear and a TOF-ratio can be calculated.

Tetanic stimulation pattern

Even when TOF-count is 0 , deeper levels of neuromuscular block can be monitored still with a post-tetanic count (PTC) stimulation pattern. To obtain a PTC, a supramaximal tetanic stimulation pattern of $50 \mathrm{~Hz}$ for 5 seconds is followed by a 3 second pause, after which a single-twitch $1 \mathrm{~Hz}$ stimulus is applied for 15 seconds. The number of muscle responses to the $1 \mathrm{~Hz}$ stimuli is related to the time of reappearance of the first twitch of a TOF stimulus ${ }^{[8]}$.

Tetanic stimulation overcomes a deep non-depolarizing block by inducing by a process called "post-tetanic facilitation": tetanic stimulus induced exhaustion of presynaptic vesicles accelerates recycling and synthesis of acetylcholine in the prejunctional synapse, a process that actual overshoots in the sense that a larger than normal amount of acetylcholine is released after a subsequent single twitch. This excessive amount of acetylcholine succeeds in overcoming a deep (competitive, non-depolarizing) neuromuscular block. Very deep levels of neuromuscular block can be quantified in this manner. A PTC of 1-2 suggests that considerable time still is needed before reappearance of the first twitch response to a TOF stimulus. The PTC pattern is typically preceded by a number of TOF stimulations and the tetanic stimulation of the PTC is only applied if no detectable responses are observed. 
Quantification of the response to stimulation: the muscle response

Following stimulation of a motor nerve, muscle response can be detected and quantified in a number of ways. Each method has various advantages and disadvantages.

\section{Manual or visual estimation}

The clinician can simply feel or observe the muscle contraction. However, manual estimation is not particularly accurate - even experienced researchers cannot observe fade at TOF ratios higher than about $40 \%{ }^{[9]}$. Because current standards mandate that TOF ratios exceed $90 \%{ }^{[10,11]}$ at the end of a procedure, manual or visual estimation is insufficient to judge whether recovery is adequate. Manual estimation is acceptable to monitor deep levels of neuromuscular block with the PTC stimulation pattern. It is generally accepted though that state-of-the-art neuromuscular monitoring requires objective quantification of muscle contraction.

\section{Mechanomyography}

Mechanomyography (MMG) measures the peak isometric muscle force after supramaximal neuromuscular stimulation. MMG is considered the "gold-standard" of neuromuscular monitoring because it is the generation of muscle force that maintains the airway and effective contraction of diaphragm ${ }^{[12]}$. However, despite its importance, there are no commercially available devices that use isometric MMG neuromuscular monitoring. MMG has been used for research purposes though.

Typically, the peak isometric muscle force of the thumb's adductor pollicis is measured after stimulating the ulnar nerve at the elbow or at the wrist. MMG requires the associated limb to remain immobile. The thumb is held immobile by fixing the forearm to an arm-board, and force is measured using a strain gauge at the thumb ${ }^{[13]}$. The resting-tension of the muscle or "preload" influences the muscle force that is generated - it is generally accepted that a preload associated muscle length of $100-125 \%$ of resting length generates maximum muscle force. At the adductor pollicis, this corresponds to a preload of approximately 200 grams, and ideally this should vary less than $25 \%$ throughout the period of neuromuscular monitoring. Obviously, the force of the preload is not exclusively conveyed to the muscle - some force is transferred to connective tissues as well. The geometry of any joints of the system also plays a role in the force produced. A drawback of the arm-board system is that subtle changes in patient positioning can change the placement of the forearm within the arm-board, which changes the resting-tension, which in turn affects interpretation of the observed muscle force.

\section{Non-isometric mechanomyography}

Related to MMG monitoring is mechanical sensing of the muscle response. In this approach muscle contraction causes bending or compression of a piezoelectric sensor. It is used in the clinically widely applied NMT MechanoSensor ${ }^{\circledR}$ (GE Healthcare, Finland) (Figure 11.1). The transducer is available in adult and paediatric sizes. Muscle preload cannot be evaluated because this depends of the mechanical properties of the transducer and how it matches with the individual anatomy. However, this approach does make attaching the device to the patient considerably simpler than for isometric systems, is much less sensitive to variation in patient positioning, and - even though it does not measure isometric muscle force - is sufficiently accurate for clinical applications.

\section{Acceleromyographic (AMG) measures}

If the limb associated with a muscle is free to move when the motor nerve is stimulated, then the movement of the limb can be also used to quantify muscle response. Acceleration is related to muscle force through Newton's second law, force $=$ mass $\times$ acceleration. Because mass remains 
constant, the peak acceleration must be proportional to the peak muscle force resulting from the activation of the motor nerve. Accelerometers are robust, wear and tear free, and inexpensive to manufacture, making them well suited for the harsh clinical environment. They are also small, allowing considerable flexibility in how they can be placed: event though most commonly used to measure thumb adduction, they can also be applied to the obicularis occuli, corrugator supercilii and the flexor hallucis brevis muscles. Many patient monitors have integrated modules which quantify the degree of neuromuscular block with accelerometry.

\section{Electromyographic measures}

Prior to generating force, action potentials propagate throughout the muscle, initiating calcium release from the sarcoplasmic reticulum. These action potentials can also be detected and used to quantify the muscle's response to neuromuscular stimulation. The summation of the action potentials can be recorded using electrodes placed over the belly of the activated muscle. The peak-to-peak amplitude or the integration of the surface underneath the electromyographic (EMG) signal can be used to quantify muscle response. The ulnar nerve is stimulated at the elbow or wrist and the EMG response captured with electrodes placed over the adductor pollicis (at the thenar eminence), the abductor digiti minimi (at the hypothenar eminence), or at the first dorsal interosseus muscle. An active recording electrode should be placed over the muscle and a ground electrode between the stimulation and the recording electrodes. Sources of artefacts are multiple. External pressure on or moving of the electrodes and the arm can make the EMG quantification unreliable, but can be avoided by properly shielding and immobilizing the arm and electrodes. Changes in temperature, electrode conditions (due to e.g. absorption of electrode gel and sweating) and monopolar diathermy can all interfere with EMG monitoring.

Neuromuscular diseases can make EMG neuromuscular monitoring problematic. Volatile anaesthetics can impair muscle function and force generation without having an effect on the EMG signal[14,15]. In general, MMG and AMG rather than EMG are often preferred as techniques to monitor the degree of a neuromuscular block because they measure the actual movement in muscles.

\section{Pharmacology of neuromuscular blocking drugs}

Several drugs can prevent the contraction of skeletal muscles at the neuromuscular junction by inhibiting the synthesis or release of acetylcholine or by blocking its actions at the postjunctional membrane. Clinically used neuromuscular blocking drugs mainly act by the latter mechanism, inhibition of the postjunctional actions of acetylcholine at the nicotinic acetylcholine receptor. Two classes of neuromuscular blocking drugs exist, non-depolarizing and depolarizing. Only one depolarizing drug is clinically used, suxamethonium (also called succinylcholine). These two drug classes have different properties.

All neuromuscular blocking drugs are quaternary ammonium compounds that hold acetylcholine somewhere in their chemical structure. The quaternary ammonium $\left(\mathrm{NH}_{4}^{+}\right)$prevents their absorption from the gastrointestinal tract, placenta and into the cerebrospinal fluid. Because of these chemical properties, neuromuscular blocking drugs are not widely distributed in the body and their volume of distribution $(0.1-0.5 \mathrm{l} / \mathrm{kg})$ is rather close to the volume of extracellular fluid ${ }^{[17]}$. 
Non-depolarizing neuromuscular blocking drugs

\section{Mechanism of action}

Chemically, non-depolarizing neuromuscular blocking drugs are either benzylisoquinolones (cisatracurium, mivacurium) or aminosteroid derivatives (rocuronium). They are competitive inhibitors of acetylcholine at the postjunctional nicotinic receptor. If they occupy one or both alpha subunits, ion channel opening is prevented and neuromuscular transmission becomes impaired. At higher concentrations they can also block the channel directly, in a non-competitive action. However, this so-called "channel block" is of minor clinical significance ${ }^{[16]}$.

\section{Adverse effects}

The action of non-depolarizing neuromuscular blocking drugs on nicotinic receptors outside the neuromuscular endplate or on muscarinic receptors explain many of their adverse effects.

Cisatracurium, mivacurium and rocuronium have essentially no effects on nicotinic receptors in the autonomic ganglia (Table 1). Via an effect on the vagal nerve, rocuronium can activate cardiac muscarinic receptors, but tachycardia will only ensue at a dose which is 3-5-fold higher than a usual dose for endotracheal intubation. Benzylisoquinolones can cause serosal mast cells to release histamine, but this effect is mild with mivacurium and absent with cisatracurium. Overall, the incidence of serious adverse effects is low. Of all intraoperative life-threatening anaphylactic or anaphylactoid reactions ( 1 in 10000 to 20000 anaesthetics in a French study), 60\% are caused by neuromuscular blocking drugs ${ }^{[17]}$.

Pharmacokinetics and pharmacodynamics of non-depolarizing neuromuscular blocking drugs Essential basic pharmacokinetic and pharmacodynamic characteristics are summarized in Table 1. Renal clearance accounts for $10-25 \%$ of the elimination of rocuronium ${ }^{[18]}$, with the remainder being excreted into bile unchanged or after metabolization by the liver. While its metabolism remains poorly understood, increased rocuronium requirements in patients ingesting enzyme inducing drugs indicate that rocuronium is at least partly metabolized by the inducible microsomal enzymes in liver. Cisatracurium is degraded by Hoffman elimination, a chemical process independent of renal or hepatic function. Mivacurium is metabolized by plasma pseudocholinesterase, which explains why its plasma clearance $(5 \mathrm{l} / \mathrm{min}$ in healthy adults) exceeds liver blood flow.

Simultaneous pharmacokinetic-dynamic modelling has been used to give a full description of the pharmacological properties of neuromuscular blocking drugs. Population pharmacokinetics is a powerful tool to identify quantitatively which factors affect the pharmacokinetics and pharmacodynamics of various drugs. The major strength of the population approach is that useful information can be extracted even from sparse data using blood samples and pharmacologic monitoring during routine efficacy studies conducted during the development of a drug. Table 2 shows the population pharmacokinetic and pharmacodynamic variables for non-depolarizing neuromuscular blocking drugs.

The model parameters shown in Table 2 allow computer simulations to be performed of the behaviour of neuromuscular blocking drugs following any proposed administration regime. Compartmental volumes V1 (central), V2 and V3 (peripheral) represent drug distribution volumes, where the drug is administered (central) and where it can diffuse or be transported while in the body. These may have vague associations with different tissues in the body due to various factors 
such as differing solubilites and other drug-tissue interactions. In any case they represent a rather extreme simplification of the complex biological processes underlying drug distribution.

Model clearance parameters such as CL (elimination), Q2 and Q3 (inter-compartmental) represent drug transport between the various compartments, with $\mathrm{CL}$ being a special case of drug transport from the central compartment out of the body or otherwise made inactive. Drugs with a higher $\mathrm{CL}$ tend to have shorter duration or action in a straightforward manner. Interestingly, they also tend to have a more rapid onset of paralysis because these drugs allow greater initial doses, creating a stronger driving force for drug distribution to the effect compartment. The rate of drug distribution to the effect site, described as $k e 0$, also plays an essential role in determining a drug's potential for rapid onset of effect. A slow keO limits the rate of onset of action. While a simple first-order rate constant is often sufficient to describe drug transport to the effect site, mivacurium is an exception to this, requiring modelling of an interstitial compartment for accurate prediction of pharmacodynamics ${ }^{[19]}$. Other PD parameters describe various characteristics of drug effect. Ce50 describes the effect-site concentration at which $50 \%$ of drug effect is achieved. Lower values for $\mathrm{Ce} 5 \mathrm{O}$ indicate higher drug potency. Parameter $\lambda$ describes the slope of the sigmoidal Emax PD model. High values of $\lambda$ indicate that drug effect changes rapidly over a low range of drug concentrations, creating an "on-off switch" like drug effect. Lower values of describe a more gradual relationship between effect-site concentration and drug effect.

To highlight the pharmacokinetic-pharmacodynamic differences between two neuromuscular blocking drugs with an intermediate duration of action, we have simulated the course of effect site concentrations after the administration of one $\mathrm{ED}_{95}$ dose of either rocuronium or cisatracurium. We also simulated context-sensitive $50 \%$ effect decrement times as a function of the duration of infusion which maintained neuromuscular block (and effect site concentration) constant (Figure 11.2).

\section{Clinical pharmacology of non-depolarizing neuromuscular blocking drugs}

Mivacurium has a shorter duration of action than rocuronium and cisatracurium, whose duration of action is considered "intermediate" (Table 1). However, because rocuronium has the shortest onset of action of all three drugs, it is the more frequently used drug, especially if rapid endotracheal intubation is required.

While cisatracurium has often been considered the drug of choice in patients having severe renal and/or hepatic dysfunction because of its organ-independent elimination, rocuronium can be used as well if the degree of neuromuscular block is monitored properly.

Non-depolarizing neuromuscular blocking drugs are most often used to provide neuromuscular block during balanced anaesthesia. Provided hypnosis is provided by other means, they may also be used to provide immobility during diagnostic procedures or during transportation of critically ill patients, and occasionally to facilitate ventilation during intensive care.

\section{Depolarizing neuromuscular blocking drugs}

Mechanism of action

The onset of action of suxamethonium is fast. Stimulation of the acetylcholine receptors usually results in visible fasciculations before the onset of muscle relaxation. Suxamethonium causes a long-lasting depolarization which prevents the muscular contraction. Experimentally, a similar 
effect can be produced by the administration of acetylcholine and anticholinesterases. Anticholinesterases augment the action of suxamethonium ${ }^{[2]}$.

\section{Adverse effects}

Because suxamethonium consists of two acetylcholine molecules (diacetylcholine), it is understandable that its adverse effects mimic those of acetylcholine. Suxamethonium has effects on cholinergic receptors all over the body, including striated muscle and autonomic nervous system (Table 1). Suxamethonium has effects on both autonomic ganglia and cardiac muscarinic receptors. Depending on the actual status of the patient's autonomic nervous system, it may cause bradycardia, tachycardia or other arrhythmias, and hypo- or hypertension. These effects can be prevented by administration of anticholinergic drugs, like atropine or glycopyrrolate.

Suxamethonium typically causes fasciculations before the onset of neuromuscular block. Many patients have also muscle pains which are more common in young muscular adults. They can be rather effectively prevented with a small dose of non-depolarizing neuromuscular drug.

Hyperkalemia and malignant hyperthermia are two life-threatening adverse effects. Plasma potassium concentrations often rise, but without clinical consequences in otherwise healthy patients. However, in patients with upper or lower motoneuron lesions, trauma, burns or immobilization, the number of extrajunctional acetylcholine receptors may be increased so much that their activation causes life-threatening hyperkalemia. Suxamethonium can trigger malignant hyperthermia, a rare autosomal dominant condition that may be fatal without prompt administration of dantrolene and effective symptomatic treatment.

Large doses or prolonged administration of suxamethonium may cause a transition of typical depolarizing block to phase II block which resembles the block produced by non-depolarizing neuromuscular drugs. Phase II block is not observed following an intubation dose of suxamethonium.

\section{Pharmacokinetics and pharmacodynamics of suxamethonium}

The duration of action of suxamethonium is 4 to 12 minutes following an intubation dose because it is rapidly metabolized by plasma pseudocholinesterase. Actually, only a small fraction of the administered dose reaches the neuromuscular end plate. The drug is thus not metabolized at the neuromuscular junction itself: in order to terminate its effect, it must diffuse back out of the neuromuscular junction into systemic circulation, where plasma pseudocholinesterase degrades it into choline and succinylmonocholine (with the latter being further metabolized to choline and succinic acid) ${ }^{[2]}$. Several genetically determined forms of plasma pseudocholinesterase exist, and this may affect the duration of action of suxamethonium. Approximately $2.5-4 \%$ of the population is carrying one abnormal gene allele, which prolongs the action of suxamethonium by 50 to $100 \%$. Another $0.04 \%$ of the population is carrying two abnormal gene alleles, and this prolongs the duration of neuromuscular block to 2-6 hours ${ }^{[20]}$.

\section{Clinical pharmacology of suxamethonium}

Because of its numerous adverse effects, the clinical use of suxamethonium has been declining. It is mainly used to facilitate endotracheal intubation, and for rapid sequence inductions in particular because it has the fastest, most reliable onset (with a consistent deep block). However, many authorities nowadays consider rocuronium ${ }^{[21]}$ a suitable alternative even for rapid sequence induction because it can easily and rapidly be reversed with sugammadex if necessary (see below). Suxamethonium also continues to be used for short-lasting muscle relaxation needed during electroconvulsive therapy or for the reposition of dislocated joints, and to treat laryngospams. 


\section{Optimal level of neuromuscular block}

Immobility is an essential part of balanced anaesthesia. Regardless of the surgical procedure, the patient should not move after a noxious stimulus. It is impossible to perform surgery if the patient is wiggling around and trying to escape the operating table. For some types of surgery, it is imperative the patient does not move because it would cause irreparable harm, e.g. during intraocular or intra-cranial surgery.

Muscle relaxation is needed when the force or pressure generated by that force makes it impossible to complete the surgical procedure, the typical example being intra-abdominal surgery. The high intra-abdominal pressures resulting from the force generated by the diaphragm and abdominal wall muscles make it impossible to perform open abdominal surgery and (somewhat more controversial, see further) laparoscopic intra-abdominal surgery. Similarly, relocation of a hip prosthesis may need relaxation.

Although immobility can be produced very selectively with neuromuscular blocking drugs, the question remains, how much neuromuscular block is enough to provide immobility and surgical relaxation. What is regarded as adequate surgical relaxation is dependent on a multitude of factors. It is not only the degree of neuromuscular block that determines the adequacy of muscle relaxation - depth of anaesthesia, type of surgery and surgical skill all have an influence. For superficial surgery, immobility is obviously required but the surgery itself does not require any significant muscle relaxation. For intra-abdominal surgery, deeper muscle relaxation may be required. What degree of neuromuscular block is needed to provide adequate surgical relaxation for what procedure has been poorly explored and is only beginning to be studied in randomized controlled trials.

For many surgical procedures, balanced anaesthesia does not need to entail the use of neuromuscular blocking drugs. Fast track cardiac surgery has been performed without muscle relaxants once the airway has been secured ${ }^{[22]}$. Surgeons rated operating conditions in the 87 patients as satisfactory, and no reversing agents were needed because the TOF ratio had recovered spontaneously to 0.90 by the end of the operation.

In accordance with the previous study, suxamethonium for facilitating endotracheal intubation was the only neuromuscular blocking drug which was needed in 86 patients undergoing spinal surgery with total intravenous anaesthesia ${ }^{[23]}$ : muscle relaxation was deemed sufficient and the surgery was successful, regardless of whether atracurium was used later during surgery or not. An isoflurane-fentanyl anaesthetic alone produced also good to excellent surgical field conditions in approximately two thirds of patients undergoing radical retropubic prostatectomy without the use of neuromuscular blocking drug. Thus, the authors concluded, that the routine use of muscle relaxants in adequately anaesthetized patients undergoing this procedure may not be indicated ${ }^{[24]}$.

During laparoscopic abdominal surgery, a $\mathrm{CO}_{2}$ pneumoperitoneum is usually needed to allow the surgeon to visualize the abdominal contents and to provide sufficient working space. Because the pressure generated by the abdominal wall muscles and diaphragm is believed to reduce the space provided by the pressurized $\mathrm{CO}_{2}$, neuromuscular blocking drugs are administered in the belief that it increases abdominal wall compliance. However, there are few studies that convincingly prove that. 
One study that did find a difference (i.e. better surgical conditions with a deep ${ }^{[25]}$ versus shallow block) was criticized because depth in the control group was not tightly controlled and because the average quality of the visual field did not differ ${ }^{[26]}$. Another study claiming "marginally better" surgical space conditions with deep rather than moderate muscle relaxation during laparoscopic cholecystectomy ${ }^{[27]}$ suffered from similar flaws, with the authors basically comparing deep versus very shallow or minimal block for a considerable portion of the surgical procedure. When patients were randomized to a deep (PTC 2-3) or a moderate neuromuscular block (TOF count 1-2) during laparoscopic bariatric surgery ${ }^{[28]}$, a deep neuromuscular block was associated with better surgical visualisation and lower pain scores in the immediate postoperative period $(p=0.03)$ (see Figure 11.3).

Two recent systematic reviews tried to clarify whether surgical conditions and patient outcome are related to the degree of neuromuscular block during surgery. Interestingly, the two reviews arrived at different conclusions. While Madsen et al. concluded that deep neuromuscular block may improve surgical conditions in laparoscopic and open abdominal surgery ${ }^{[29]}$, Kopman and Naguib $^{[30]}$ stated that there are little objective data to demonstrate that a deep neuromuscular block (PTC $\geq 1$ with TOF twitch count $=0$ ) improves surgical conditions or patient outcome compared to a moderate block (TOF twitch count $=1-3$ ). Kopman and Naquib were also concerned about the economic consequences of the increasing use of sugammadex which cannot be avoided if a deep neuromuscular block is deemed necessary until the very end of surgery. More information can be found in 2 editorials that discuss the relationship between surgical muscle relaxation and degree of neuromuscular block and that try to define "adequacy of muscle relaxation" ${ }^{\prime 31,32]}$.

To summarize, for many surgical procedures no consensus has been reached regarding the optimal level of neuromuscular blocking drug-induced block. While different types of operations need different levels of muscle relaxation, it is important to realize this depends on both the depth of anaesthesia and the degree of neuromuscular block: deeper levels of anaesthesia may allow shallower neuromuscular block to obtain the same degree of relaxation. The price to pay for using a deep level of anaesthesia as an essential component of muscle relaxation is prolonged emergence. If surgery requires deep muscle relaxation until the very end of surgery and if this accomplished by deep level of drug-induced neuromuscular block (e.g. a PTC of 1-3), sugammadex can be used to antagonize the block, but this comes with a price tag; the only alternative under these conditions is to wait for the spontaneous recovery.

Factors affecting the requirements of neuromuscular blocking drugs

The dose of neuromuscular blocking drugs obviously depends on the desired degree of neuromuscular block. However, there are other factors that affect the requirements of neuromuscular blocking drugs.

\section{Drug-drug interactions}

Drugs that inhibit plasma cholinesterase may delay neuromuscular recovery after suxamethonium administration. These drugs include anticholinesterase inhibitors (donepezil, ecothiopate, neostigmine, pyridostigmine, rivastigmine etc.), antineoplastic drug cyclophosphamide, bambuterol and the monoamine oxidase inhibitor phenelzine ${ }^{[33]}$.

Enzyme inducing drugs like rifampicin and older antiepileptic drugs antagonize the neuromuscular blocking effects of rocuronium, probably by enhancing their hepatic elimination (although other mechanisms may also contribute ${ }^{[34]}$. The mechanism by which phenytoin and carbamazepine 
antagonize cisatracurium is not known ${ }^{[35,36]}$. Enzyme induction or inhibition does not affect mivacurium $^{[37]}$.

Volatile anaesthetics potentiate the effects of non-depolarizing muscle relaxants in a dosedependent manner, an effect most pronounced with desflurane (Figure 11.4) ${ }^{[38]}$. The underlying mechanism remains controversial, and several factors have been invoked: increased muscle blood flow, increased sensitivity of the motor end-plate, decreased release of acetylcholine, change of ion-channel conductance, or other effects at central nervous system.

Aminoglycosides, polymyxins, lincomycin and clindamycin all can potentiate a neuromuscular block $^{[33]}$ by inhibiting the prejunctional release of acetylcholine and by depressing postjunctional acetylcholine receptor sensitivity to acetylcholine.

\section{Hypothermia \\ Hypothermia affects the pharmacokinetics and/or pharmacodynamics of non-depolarizing neuromuscular blocking drugs ${ }^{[39]}$. Hypothermia at $30.4{ }^{\circ} \mathrm{C}$ causes a $50 \%$ reduction in rocuronium plasma clearance, reducing rocuronium requirements in a hypothermic patient ${ }^{[40]}$. Hypothermia also reduces the Hoffman elimination process which prolongs the action of cisatracurium ${ }^{[41,42]}$. Hypothermia also affects the neuromuscular monitoring process itself: if the monitored arm becomes hypothermic, the onset and duration of action of the drugs will become slower and longer, respectively, than in the more centrally located muscles (e.g. abdominal wall and diaphragm) at normal core temperature ${ }^{[43]}$.}

\section{Dosing of neuromuscular blocking drugs}

\section{Initial administration}

A relative overdose administered as an intravenous bolus achieves the most rapid onset of neuromuscular block during induction of anaesthesia. The blood rapidly transports the drug to the neuromuscular junctions of the body where its pharmacologic effects take place. The initial dose is higher than that required to attain those peak concentration levels needed at the neuromuscular junction to facilitate endotracheal intubation. Typically, the initial dose is two to four times the $E_{95}$. ED 95 is the dose which is required to induce a 95\% neuromuscular block (the height of the first twitch in the train-of-four sequence reaches $5 \%$ of the height of the control twitch obtained before the administration of neuromuscular blocking drugs). In general, the accompanying overshoot is not deleterious because a moderate overdose of modern competitive neuromuscular blocking drugs has little or no adverse effects. However, the prolonged duration of drug effect can be problematic for short procedures.

\section{Intermittent bolus dosing}

Most often, a neuromuscular block is maintained by repeated bolus doses. Because of the large margin of safety (or neuromuscular reserve) of the neuromuscular junction, the maintenance dose is considerably smaller than the induction dose: even though monitoring shows the block induced by the loading dose is recovering, up to $70 \%$ of the postjunctional nicotinic receptors may still be blocked, a condition under which even a small top up dose can have a profound effect on the twitch response. Figure 11.5 shows the time course of neuromuscular block following intermittent bolus doses. The degree of neuromuscular block varies throughout the procedure, reaching barely adequate levels just before administration of the maintenance dose and usually achieving complete block for a period thereafter. 


\section{Continuous infusion}

One way to improve stability of the neuromuscular block over time is to start an infusion once the muscle starts to recover from the induction dose (Figure 11.6). The infusion rates of most neuromuscular blocking drugs to accomplish this have been published. Typical values for rates of infusion required to maintain neuromuscular block constant at $95 \%$ are given in Table 1 . However, because of major interindividual differences, it is important to quantify the degree of neuromuscular block repetitively and adjust the rate of infusion accordingly.

\section{Computer-controlled infusion}

Short-acting neuromuscular blocking drugs can also be administered via a computer-controlled infusion. Both target-controlled and closed-loop controlled systems have been described. At least theoretically, target-controlled infusion systems are able to attain and maintain the desired concentration of the neuromuscular blocking drug. Vermeyen et al. and Motamed et al. have described a target-controlled infusion system for the infusion of rocuronium ${ }^{[44,45]}$ and Ma et al. ${ }^{[46]}$ for cisatracurium.

Although the target-controlled infusion of neuromuscular blocking drugs can obviously maintain the concentrations at a reasonably constant level, they cannot be used without the monitoring of neuromuscular block. Without adaptation of the model parameters during drug administration, the control of neuromuscular block is far from optimal as compared to closed-loop control of neuromuscular block. The values for median performance error and median absolute performance error (expressed as median with range) during target-controlled infusion of rocuronium were 9.7 $(-35,40)$ and $23.6(5,40) \%$ without adaptation of the model parameters and $14.8(11,44)$ and 16 $(13,44) \%$ with Bayesian forecasting of parameters ${ }^{[45]}$. These figures are far from the values of median performance error and median absolute performance error obtained for closed loop control of rocuronium infusion. For instance, Kansanaho and Olkkola ${ }^{[47]}$ observed that the values of median performance error and median absolute performance error (expressed as median with $25^{\text {th }}$ and $75^{\text {th }}$ percentile) were $0.5(0.0,0.9)$ and $1.3(1.1,1.7) \%$, respectively.

Figure 11.7 depicts the typical course of neuromuscular block during closed-loop control. The closed-loop system can be started any time after the initial bolus, and will deliver only that amount of drug needed to achieve the target neuromuscular block level. Theoretically, it should be able to render a neuromuscular block even more stable than with continuous infusions. Longacting drugs are less suitable for use with closed-computer-controlled infusion because fewer dose adjustments will be needed - and it is precisely that what a computer-controlled infusion is well suited for. While it could be applied during long-term sedation in the intensive care unit, any benefit should be weighed against that of using short-acting drugs in this context, a benefit not likely to be clinically relevant.

A closed-loop system is used to steer drug delivery by the computer-controlled pump (also see Weber chapter). Actually, neuromuscular blocking drugs were amongst the first anaesthetic drugs to be administered with this technology (see below). The first component is a signal quantifying a patient's neuromuscular block. The signal obtained automatically and repeatedly is fed back to a controller where it is compared to a desired "target". The computer then applies algorithms on the various inputs it receives from the actual and desired states of neuromuscular block. Time and time-differences can also be used as inputs for the algorithm. Next, the computer adjusts the injection rate of syringe pump loaded with neuromuscular blocking drugs to achieve the desired block. 
The advantages of closed-loop infusions of neuromuscular blocking drugs are several-fold. First, it allows anaesthesiologists to focus on other aspects of care by freeing up time that may otherwise be needed for tedious repetitive dose calculations. It may also avoid "cognitive-overload" in particularly complex cases. Second, complex control algorithms can be implemented, allowing one to achieve a more stable neuromuscular block more rapidly than is possible with direct human control. Finally, control algorithms can more accurately monitor dosing histories, provide feedback, or trigger alarms to warn the anaesthesiologist about potential over- or under-dosing.

Of course, these systems have disadvantages as well. First, some systems require time and attention to be set up. This includes entering patient covariates (weight, age, etc.), neuromuscular block targets, filling and placement of syringes. For some systems, these tasks have to be completed before anaesthesia can be started. This increases clinical workload during the busy induction period, precisely when clinicians need to focus on a host of other factors. Second, increased technical complexity may introduce new sources of error and failure. Patient information can be entered incorrectly, syringes can be empty and/or need replacement, syringes can be incorrectly filled, etc. Understanding potential workflow errors and their consequences for patient care (as well as preventing them) is a complex undertaking.

Despite the fact that closed-loop control of neuromuscular blocking drugs has a surprisingly long history, and despite a plethora of closed-loop systems described in anaesthesia research, no such systems have found broad commercial application. One reason for this are the limitations inherent in many of the control algorithms. For example, adaptive and model-based systems "learn" individual characteristics based on the history of applied doses and recorded responses, which means the computer needs to have all dosing information. This precludes clinicians from dosing "along-side" a control system because doses given by the clinician outside of the control algorithm may be interpreted by the algorithm as increased sensitivity of the patient to neuromuscular blocking drugs. The algorithm may consequently administer lower drug doses than needed to maintain the desired effect, because it will rely on this (incorrect) high sensitivity and decrease the injection rate. Complex stability issues can occur, causing poor performance resulting in a clinically insufficient neuromuscular block.

Avoiding the potential issues with complex control algorithms requires abandoning some degrees of "adaptation" in the control algorithm. This has been successful in some ways: a simple nonadaptive proportional-integrative-derivative controller combined with a lookup-table for TOF counts has been shown to achieve good stability in muscle relaxation, while maintaining adequate performance despite relaxant dosing "along-side" the control algorithm ${ }^{[48]}$. The system even performed adequately during power-cycling (switching it off and then on again) during the surgical procedure. Despite some initial system development, the proposed system was never offered commercially.

\section{Reversal of neuromuscular block}

If the effect of neuromuscular blocking drugs is not monitored with objective methods, the patient is at risk for residual neuromuscular block at the end of the procedure. If the patient is extubated before the TOF ratio has reached at least 0.9 , there is an increased risk for reduced acute hypoxic ventilatory response and aspiration (the laryngeal muscles that prevent this from happening are very sensitive to neuromuscular blocking drugs). Because the risk of postoperative complications is markedly increased in patients with a postoperative residual neuromuscular block ${ }^{[49]}$, a residual neuromuscular block has to be antagonized. The action of suxamethonium cannot be reversed. If 
it would cause a prolonged block (e.g. in a patient with atypical pseudocholinesterases), the patient has to be ventilated until the block has worn off. Theoretically one could also administer fresh frozen plasma, but it usually regarded safer to wait for the recovery of the neuromuscular block.

The action of non-depolarizing neuromuscular blocking drugs, however, can be pharmacologically reversed. The conventional way of antagonizing the neuromuscular block is the administration of anticholinesterases together with anticholinergic drugs. Because non-depolarizing neuromuscular drugs produce the block by competitive antagonism, the effect can be overcome and reversed by increasing the concentration of the agonist acetylcholine. The most commonly used anticholinesterases are neostigmine and edrophonium which are combined with glycopyrrolate or atropine to counteract the stimulation of muscarinic receptors. The onset time of neostigmine matches that of glycopyrrolate while the onset time of edrophonium matches that of atropine. When using anticholinesterases, reversal should not be attempted until the recovery of the neuromuscular junction can be observed. Deep neuromuscular block cannot be antagonized with anticholinesterases. At least two, but preferably three to four twitches should be observable in the train-of-four sequence. Anticholinesterases can be used to antagonize the block induced by any of the non-depolarizing neuromuscular drugs.

The action of the aminosteroid rocuronium can also be antagonized with the cyclodextrin derivative sugammadex. Sugammadex forms tight complexes with rocuronium. After administration of sugammadex the free concentration of rocuronium decreases rapidly. The resulting concentration gradient between plasma and neuromuscular junction rapidly decreases the concentration of rocuronium at the postjunctional nicotinic receptors, terminating rocuronium's neuromuscular blocking effect within minutes. The sugammadex-rocuronium complex is excreted unchanged into urine, and has an elimination half-life of approximately two hours. Sugammadex is effective at any depth of neuromuscular block; its efficacy is not affected by the type and depth of anaesthesia ${ }^{[50]}$.

Prior administration of sugammadex affects subsequent rocuronium dosing requirements. According to the manufacturer's recommendation, after $4 \mathrm{mg} / \mathrm{kg}$ of sugammadex, no rocuronium should not be given in the ensuing 5 minutes. If rocuronium were to be given within this 5 -minute period, the dose should be $1.2 \mathrm{mg} / \mathrm{kg}$. Even then, the onset of neuromuscular block is delayed and the duration action is likely to be markedly reduced. After $16 \mathrm{mg} / \mathrm{kg}$ of sugammadex, the manufacturer recommends not to use rocuronium for $24 \mathrm{~h}$. If a neuromuscular blocking drug is required soon after the administration of sugammadex, most anaesthesiologists would choose one of the benzylisoquinolone derivatives, because their action is not modified by sugammadex.

\section{Conclusions and recommendations}

Immobility and sufficient surgical muscle relaxation are essential components of balanced anaesthesia. Although they can be accomplished selectively with neuromuscular blocking drugs, adequate muscle relaxation during anaesthesia also depends on the depth of anaesthesia.

Although neuromuscular blocking drugs have been administered by continuous infusion and with computer controlled infusion, an intermittent bolus is the more frequently used administration method. The initial dose of non-depolarizing neuromuscular blocking drugs is normally 2-4 times the $\mathrm{ED}_{95}$ dose, followed by smaller doses to maintain the neuromuscular block. 
The degree of neuromuscular block should always be measured with objective monitoring methods. Full neuromuscular recovery (TOF ratio $>0.90$ ) must be ensured before the waking up of the patient at the end of the anaesthetic. Residual neuromuscular block considerably increases the risk for reduced acute hypoxic ventilatory response, aspiration and other serious postoperative complications. 


\section{Legends to the illustrations}

Figure 11.1. Monitoring of neuromuscular block with the Mechanosensor ${ }^{\circledR}$ is based on bending of a piezoelectric sensor.

Figure 11.2. Left panel: Simulated effect site concentrations of rocuronium and cisatracurium after the administration of one $\mathrm{ED}_{95}$ dose of each drug. Right panel: Context-sensitive $50 \%$ effect decrement times as a function of the duration of rocuronium and cisatracurium infusions which maintained neuromuscular block (and effect site concentration) constant. Simulation were based on the parameters obtained from Ploeger ${ }^{[51]}$, Kleijn ${ }^{[52]}$, Proost ${ }^{[53]}$, Schmith $^{[54]}$, Liu ${ }^{[55]}$, and $\operatorname{Tran}^{[56]}$.

Figure 11.3. Influence of deep relaxation on surgical conditions scored with Leiden-surgical rating scale (L-SRS, mean with $95 \% \mathrm{Cl}$ ) from 1 (extremely poor) to 5 (optimal conditions) in laparoscopic bariatric surgery. ${ }^{*}$ Mann-Whitney- $U$ test $\mathrm{P}<0.01$ versus moderate block.

Figure 11.4. The rate of infusion cisatracurium maintaining neuromuscular block constant at $90 \%$ in patients anaesthetized with desflurane, isoflurane, sevoflurane or propofol. ${ }^{*} \mathrm{P}<0.02$ as compared to the other groups, ${ }^{* *} \mathrm{P}<0.002$ as compared to patients with volatile anaesthetics.

Figure 11.5. Maintenance of neuromuscular block using intermittent bolus dosing. The degree of neuromuscular block varies throughout the procedure between barely adequate and complete neuromuscular block.

Figure 11.6. Maintenance of neuromuscular block using a continuous infusion. Compared to the intermittent bolus dosing, the degree of neuromuscular block varies considerably less throughout the procedure.

Figure 11.7. Maintenance of neuromuscular block using a computer-controlled, "closed-loop" system. 
Table 1. Effect of commonly used neuromuscular blocking drugs on the autonomic nervous system and histamine release and their basic pharmacokinetic and pharmacodynamic properties

\begin{tabular}{|c|c|c|c|c|c|c|c|c|c|}
\hline \multirow[b]{2}{*}{ Drug } & \multirow[b]{2}{*}{ Chemical structure } & \multicolumn{3}{|c|}{$\begin{array}{l}\text { Autonomic nervous system and } \\
\text { histamine release }\end{array}$} & \multicolumn{5}{|c|}{ Basic pharmacokinetic and pharmacodynamic properties } \\
\hline & & $\begin{array}{l}\text { Autonomic } \\
\text { ganglia }\end{array}$ & $\begin{array}{l}\text { Cardiac } \\
\text { muscarinic } \\
\text { receptor }\end{array}$ & $\begin{array}{l}\text { Histamine } \\
\text { release }\end{array}$ & $\begin{array}{l}\text { ED95 } \\
\text { (mg/kg) }\end{array}$ & $\begin{array}{l}\text { Rate of infusion } \\
\text { required to } \\
\text { maintain } \\
\text { neuromuscular } \\
\text { block at } 95 \% \\
\text { ( } \mu \mathrm{g} / \mathrm{kg} / \mathrm{min} \text { ) }\end{array}$ & $\begin{array}{l}\text { Time to } \\
\text { peak } \\
\text { effect } \\
\text { following } \\
2 \times \text { ED }_{95} \\
\text { (min) }\end{array}$ & $\begin{array}{l}\text { Time to T1 } \\
=25 \% \text { of } \\
\text { control } \\
\text { following } 2 \\
\times \text { ED } \\
\text { (min) }\end{array}$ & $\begin{array}{l}\text { Renal } \\
\text { clearance } \\
\text { (\% total } \\
\text { clearance) }\end{array}$ \\
\hline Cisatracurium & Benzylisoquinoline & None & None & None & 0.05 & $1-2$ & 5.2 & $20-50$ & 16 \\
\hline Mivacurium & Benzylisoquinoline & None & None & Slight & 0.08 & 3-15 & 3 & $10-20$ & $<5$ \\
\hline Rocuronium & Aminosteroid & None & $\begin{array}{l}\text { Blocks } \\
\text { weakly }\end{array}$ & None & 0.3 & $9-12$ & 1.5 & $20-50$ & $10-25$ \\
\hline Suxamethonium & Diacetylcholine & Stimulates & Stimulates & Slight & 0.3 & - & 1.4 & $<10$ & $<2$ \\
\hline
\end{tabular}

$E D_{95}$ is the dose which is required to induce a $95 \%$ neuromuscular block (the height of the first twitch in the train-of-four sequence reaches $5 \%$ of the height of the control twitch obtained before the administration of neuromuscular blocking drugs) 
Table 2. Population pharmacokinetic and pharmacodynamic variables for non-depolarizing neuromuscular blocking drugs.

\begin{tabular}{|c|c|c|c|c|c|}
\hline & Author & Subgroup & Pharmacokinetics & & Pharmacodynamics \\
\hline \multirow[t]{6}{*}{ Cistratcurium } & \multirow{2}{*}{\multicolumn{2}{|c|}{ Schmith $^{[54]}$}} & $\mathrm{V} 1=0.0457 \cdot \mathrm{WGT} \mathrm{I}$ & $\mathrm{CL}=0.00457 \cdot \mathrm{WGT} \mathrm{I} / \mathrm{min}$ & $\mathrm{ke} 0=0.05751 / \mathrm{min}$ \\
\hline & & & V2=0.0988.WGT I & $\mathrm{Q} 2=0.00569 \cdot \mathrm{WGT} \mathrm{l} / \mathrm{min}$ & $\begin{array}{l}\mathrm{Ce} 50=141 \mathrm{ng} / \mathrm{ml} \\
\lambda=4.01\end{array}$ \\
\hline & \multirow[t]{2}{*}{ Lui $^{[55]}$} & \multirow[t]{2}{*}{ control group } & $\mathrm{V} 1=0.0583 \cdot \mathrm{WGT} \mathrm{I}$ & $\mathrm{CL}=0.00642 \cdot \mathrm{WGT} \mathrm{I} / \mathrm{min}$ & $\mathrm{ke} 0=0.14 \mathrm{1} / \mathrm{min}$ \\
\hline & & & $\mathrm{V} 2=0.0428 \cdot \mathrm{WGT} \mathrm{I}$ & $\mathrm{Q} 2=0.0180 \cdot \mathrm{WGT}$ & $\begin{array}{l}\text { Ce50=198.8 ng } / \mathrm{ml} \\
\lambda=6.96\end{array}$ \\
\hline & \multirow{2}{*}{\multicolumn{2}{|c|}{$\operatorname{Tran}^{[56]}$}} & $\mathrm{V} 1=0.035 \cdot \mathrm{WGT} I$ & $\mathrm{CL}=0.0037 \cdot \mathrm{WGT} \mathrm{I} / \mathrm{min}$ & $\mathrm{ke} 0=0.0541 / \mathrm{min}$ \\
\hline & & & $\mathrm{V} 2=0.0511 \cdot \mathrm{WGT} I$ & $\mathrm{Q} 2=0.00367 \cdot \mathrm{WGT} \mathrm{l} / \mathrm{min}$ & $\begin{array}{l}\text { Ce } 50=153 \mathrm{ng} / \mathrm{ml} \\
\lambda=6.9\end{array}$ \\
\hline \multirow{3}{*}{ Mivacurium } & \multirow{3}{*}{\multicolumn{2}{|c|}{ Schiere et. al. ${ }^{[19]}$}} & $\mathrm{V} 1=0.0397 \cdot \mathrm{WGT} \mathrm{I}$ & $\mathrm{CL}=0.031 \cdot \mathrm{WGT} \mathrm{I} / \mathrm{min}$ & kip $=0.3741 / \mathrm{min}$ (plasma-interstitial) \\
\hline & & & $\mathrm{V} 2=0.0194 \cdot \mathrm{WGT} \mathrm{I}$ & $\mathrm{Q} 2=0.00464 \cdot \mathrm{WGT} \mathrm{l} / \mathrm{min}$ & kei $=0.151$ 1/min (interstitial-effect) \\
\hline & & & & & $\begin{array}{l}\mathrm{Ce} 50=98 \mathrm{mg} / \mathrm{ml} \\
\lambda=3.7\end{array}$ \\
\hline \multirow[t]{14}{*}{ Rocuronium } & \multirow[t]{6}{*}{ Ploeger ${ }^{[51]}$} & Caucasians & $\mathrm{V} 1=3.58 \mathrm{I}$ & $\mathrm{CL}=0.353 \mathrm{l} / \mathrm{min}$ & \multirow{6}{*}{$\begin{array}{l}\mathrm{ke} 0=0.6551 / \mathrm{min} \\
\mathrm{Ce} 50=720 \mathrm{ng} / \mathrm{ml} \\
\lambda=6.57\end{array}$} \\
\hline & & & $\mathrm{V} 2=3.26 \mathrm{I}$ & $\mathrm{Q} 2=0.565 \mathrm{l} / \mathrm{min}$ & \\
\hline & & & $\mathrm{V} 3=7.64 \mathrm{I}$ & $\mathrm{Q} 3=0.134 \mathrm{l} / \mathrm{min}$ & \\
\hline & & Japanese & $\mathrm{V} 1=2.56 \mathrm{I}$ & $\mathrm{CL}=0.252 \mathrm{I} / \mathrm{min}$ & \\
\hline & & & $V 2=3.26 \mathrm{I}$ & $\mathrm{Q} 2=0.354 \mathrm{l} / \mathrm{min}$ & \\
\hline & & & $V 3=4.42 \mathrm{I}$ & $\mathrm{Q} 3=0.0584 \mathrm{I} / \mathrm{min}$ & \\
\hline & \multirow{5}{*}{\multicolumn{2}{|c|}{ Kleijn ${ }^{[52]}$}} & $\mathrm{V} 1_{\mathrm{cr}} \cdot 4.74 \cdot \mathrm{WGT} / 70$ & $\mathrm{Clage} \cdot 0.269 \cdot(\mathrm{WGT} / 70)^{0.75}$ & $\mathrm{ke}=\mathrm{Ksev} \cdot 0.134 \cdot(\mathrm{WGT} / 70)^{-0.25} 1 / \mathrm{min}$ \\
\hline & & & $V_{c r}=\exp (-0.00143 \cdot(C R-119))$ & $C_{\text {lage}}=1-0.00678 \cdot(\mathrm{AGE}-43)$ & Ksev $=1-(\mathrm{Sev}) 0.567$ \\
\hline & & & V2 age $6.76 \cdot W G T / 70$ & Q2rac $0.279 \cdot(\mathrm{WGT} / 70)^{0.75}$ & Ce50=Esev $1.62 \mu \mathrm{M}$ \\
\hline & & & $V 2_{\text {age }}=\exp (0.00613 \cdot(A G E-43))$ & Q2rac $=1-($ Asian $) 0.212$ & Esev=1-(Sev) 0.395 \\
\hline & & & & & $\lambda=7.52$ \\
\hline & \multirow{3}{*}{\multicolumn{2}{|c|}{$\operatorname{Proost}^{[53]}$}} & $\mathrm{V} 1=0.0372 \cdot \mathrm{WGT}$ & $\mathrm{CL}=0.00422 * \mathrm{WGT}$ & $\mathrm{ke} 0=0.137 \mathrm{1} / \mathrm{min}$ \\
\hline & & & $\mathrm{V} 2=0.0370 \cdot \mathrm{WGT}$ & $\mathrm{Q} 2=0.00617 \cdot \mathrm{WGT}$ & $\mathrm{Ce} 50=1257 \mathrm{mg} / \mathrm{ml}$ \\
\hline & & & V3 $=0.114 * W G T$ & $Q 3=0.00185 \cdot W G T$ & $\lambda=3.68$ \\
\hline
\end{tabular}

Muotoiltu: ruotsi (Ruotsi)

Muotoiltu: ruotsi (Ruotsi)

Muotoiltu: ruotsi (Ruotsi)

Muotoiltu: ruotsi (Ruotsi)

Muotoiltu: ruotsi (Ruotsi)

Muotoiltu: ruotsi (Ruotsi) 


\section{References}

1 Tammisto T, Olkkola KT. Dependence of the adequacy of muscle relaxation on the degree of neuromuscular block and depth of enflurane anesthesia during abdominal surgery. Anesth Analg 1995; 80: 543-7.

2 Hibbs RE, Zambon AC. Agents Acting at the Neuromuscular Junction and Autonomic Ganglia. In: Brunton LL, Chabner BA, Knollmann BC. eds. Goodman \& Gilman's: The Pharmacological Basis of Therapeutics, 12e New York, NY: McGraw-Hill;

http://accessmedicine. mhmedical.com/content. aspx ?bookid=1613\&sectionid=102158134.

(Accessed March 31, 2017.)

3 Bowman WC, Prior C, Marshall IG. Presynaptic receptors in the neuromuscular junction. Ann NY Acad Sci 1990; 604: 69-81.

4 Hemmerling TM, Donati F. Neuromuscular blockade at the larynx, the diaphragm and the corrugator supercilii muscle: a review. Can J Anesth 2003; 50: 779-94.

5 Viby-Mogensen J, Engbaek J, Eriksson LI, Gramstad L, Jensen E, Jensen FS, Koscielniak-Nielsen Z, Skovgaard LT, $\varnothing$ stergaard D. Good clinical research practice (GCRP) in pharmacodynamic studies of neuromuscular blocking agents. Acta Anaesthesiol Scand 1996; 40: 59-74.

6 Fuchs-Buder T, Claudius C, Skovgaard LT, Eriksson LI, Mirakhur RK, Viby-Mogensen J. Good clinical research practice in pharmacodynamic studies of neuromuscular blocking agents II: the Stockholm revision. Acta Anaesthesiol Scand 2007; 51: 789-808.

7 Eleveld DJ, Kopman AF, Proost JH, Wierda JM. Model to describe the degree of twitch potentiation during neuromuscular monitoring. Brit J Anaesth 2004; 92: 373-80.

8 El-Orbany MI, Joseph NJ, Salem MR. The relationship of posttetanic count and train-of-four responses during recovery from intense cisatracurium-induced neuromuscular blockade. Anesth Analg 2003; 97: 80-4.

9 Viby-Mogensen J, Jensen NH, Engbaek J, Ording H, Skovgaard LT, Chraemmer-Jorgensen B. Tactile and visual evaluation of the response to train-of-four nerve stimulation. Anesthesiology 1985; 63: 440-3.

10 Eikermann M, Groeben H, Husing J, Peters J. Predictive value of mechanomyography and accelerometry for pulmonary function in partially paralyzed volunteers. Acta Anaesthesiol Scand 2004; 48: 365-70.

11 Capron F, Alla F, Hottier C, Meistelman C, Fuchs-Buder T. Can acceleromyography detect low levels of residual paralysis? A probability approach to detect a mechanomyographic train-of-four ratio of 0.9. Anesthesiology 2004; 100: 1119-24

12 Viby-Mogensen J, Engbaek J, Eriksson LI, Gramstad L, Jensen E, Jensen FS, Koscielniak-Nielsen Z, Skovgaard LT, Ostergaard D. Good clinical research practice (GCRP) in pharmacodynamic studies of neuromuscular blocking agents. Acta Anaesthesiol Scand 1996; 40: 59-74.

13 Rowaan CJ, Vandenbrom RH, Wierda JM. The Relaxometer: a complete and comprehensive computer-controlled neuromuscular transmission measurement system developed for clinical research on muscle relaxants. J Clin Monit 1993; 9: 38-44.

14 Weber S, Muravchick S. Monitoring technique affects measurement of recovery from succinylcholine. J Clin Monit 1987; 3: 1-5.

15 Kopman AF. The relationship of evoked electromyographic and mechanical responses following atracurium in humans. Anesthesiology 1985; 63: 208-11.

16 Colquhoun D, Dreyer F, Sheridan RE. The actions of tubocurarine at the frog neuromuscular junction. J Physiol 1979; 293: 247-84. 
17 Mertes PM, Laxenaire PM, Alla F. Anaphylactic and anaphylactoid reactions occurring during anesthesia in France in 1999-2000. Anesthesiology 2003; 99: 536-45.

18 Atherton DPL, Hunter JM. Clinical pharmacokinetics of the newer neuromuscular blocking drugs. Clin Pharmacokinet 1999; 36: 169-89.

19 Schiere S, Proost JH, Roggeveld J, Wierda M. An interstitial compartment is necessary to link the pharmacokinetics and pharmacodynamics of mivacurium. European journal of anaesthesiology. 2004 Nov;21(11):882-91.

20 Jensen FS, Viby-Mogensen J. Plasma cholinesterase and abnormal reaction to succinylcholine: twenty years' experience with the Danish Cholinesterase Research Unit. Acta Anaesthesiol Scand 1995; 39: 150-6.

21 Andrews JI, Kumar N, van den Brom RHG, Olkkola KT, Roest GJ, Wright PMC. A large simple randomized trial of rocuronium versus succinylcholine in rapid sequence induction of anaesthesia along with propofol. Acta Anaesthesiol Scand 1999; 43: 4-8.

22 Gueret G, Rossignol B, Kiss G, Wargnier JP, Miossec A, Spielman S, Arvieux CC. Is muscle relaxant necessary for cardiac surgery? Anesth Analg 2004; 99: 1330-3.

$23 \mathrm{Li}$ YL, Liu YL, Xu CM, Lv XH, Wan ZH. The effects of neuromuscular blockade on operating conditions during general anesthesia for spinal surgery. J Neurosurg Anesthesiol 2014; 26: 45-9. 24 King M, Sujirattanawimol N, Danielson DR, Hall BA, Schroeder DR, Warner DO. Requirements for muscle relaxants during radical retropubic prostatectomy. Anesthesiology 2000; 93: 1392-7. 25 Dubois PE, Putz L, Jamart J, Marotta ML, Gourdin M, Donnez O. Deep neuromuscular block improves surgical conditions during laparoscopic hysterectomy: a randomised controlled trial. Eur J Anaesthesiol 2014; 31: 430-6.

26 Kopman AF, Naguib M. Laparoscopic surgery and muscle relaxants. Is deep block helpful? Anesth Analg 2015; 120: 51-8

27 Staehr-Rye AK, Rasmussen LS, Rosenberg J, Juul P, Lindekaer AL, Riber C, Gätke MR. Surgical space conditions during low-pressure laparoscopic cholecystectomy with deep versus moderate neuromuscular blockade: a randomized clinical study. Anesth Analg 2014; 119: 1084-92.

28 Torensma B, Martini CH, Boon M, Olofsen E, In 't Veld B, Liem RS, Knook MT, Swank DJ, Dahan A. Deep Neuromuscular Block Improves Surgical Conditions during Bariatric Surgery and Reduces Postoperative Pain: A Randomized Double Blind Controlled Trial. PLoS One 2016; 11: e0167907. 29 Madsen MV, Staehr-Rye AK, Gätke MR, Claudius C. Neuromuscular blockade for optimising surgical conditions during abdominal and gynaecological surgery: a systematic review. Acta Anaesthesiol Scand 2015; 59: 1-16.

30 Kopman AF, Naguib M. Laparoscopic surgery and muscle relaxants. Is deep block helpful? Anesth Analg 2015; 120: 51-8.

31 Kopman AF, Naguib M. Is deep neuromuscular block beneficial in laparoscopic surgery? No, probably not. Acta Anaesthesiol Scand 2016; 60: 717-22.

32 Madsen MV, Staehr-Rye AK, Claudius C, Gatke MR. Is deep neuromuscular blockade beneficial in laparoscopic surgery? Yes, probably. Acta Anaesthesiol Scand 2016; 60: 710-6.

33 Aronson JK. Meyler's Side Effects of Drugs, 16th Edition, Amsterdam-Oxford: Elsevier, 2015. 34 Spacek A, Neiger FX, Krenn CG, Hoerauf K, Kress HG. Rocuronium-induced neuromuscular block is affected by chronic carbamazepine therapy. Anesthesiology 1999; 90: 109-12.

35 Koenig MH, Edwards LT. Cisatracurium-induced neuromuscular blockade in anticonvulsant treated neurosurgical patients. J Neurosurg Anesthesiol 2000; 12: 314-8.

36 Richard A, Girard F, Girard DC, Boudreault D, Chouinard P, Moumdjian R et al. Cisatracuriuminduced neuromuscular blockade is affected by chronic phenytoin or carbamazepine treatment in neurosurgical patients. Anesth Analg 2005; 100: 538-44. 
37 Spacek A, Neiger FX, Spiss CK, Kress HG. Chronic carbamazepine therapy does not influence mivacurium-induced neuromuscular block. Br J Anaesth 1996; 77: 500-2.

38 Hemmerling TM, Schuettler J, Schwilden H. Desflurane reduces the effective therapeutic infusion rate (ETI) of cisatracurium more than isoflurane, sevoflurane, or propofol. Can J Anesth 2001; 48: 532-7.

39 Caldwell JE, Heier T, Wright PM, Lin S, McCarthy G, Szenohradszky J, Sharma ML, Hing JP, Schroeder M, Sessler DI. Temperature-dependent pharmacokinetics and pharmacodynamics of vecuronium. Anesthesiology 2000; 92: 84-93.

40 Beaufort AM, Wierda JM, Belopavlovic M, Nederveen PJ, Kleef UW, Agoston S. The influence of hypothermia (surface cooling) on the time-course of action and on the pharmacokinetics of rocuronium in humans. Eur J Anaesthesiol Suppl. 1995; 11: 95-106.

41 Stenlake JB, Hughes R. In vitro degradation of atracurium in human plasma. Br J Anaesth 1987; 59: 806-7.

42 Cammu G, Coddens J, Hendrickx J, Deloof T. Dose requirements of infusions of cisatracurium or rocuronium during hypothermic cardio pulmonary bypass. Br J Anaesth 2000; 84: 587-90. 43 Eriksson LI, Viby-Mogensen J, Lennmarken C. The effect of peripheral hypothermia on vecuronium-induced neuromuscular block. Acta Anaesthesiol Scand 1991; 35: 387-92.

44 Vermeyen KM, Hoffmann VL, Saldien V. Target controlled infusion of rocuronium: analysis of effect data to select a pharmacokinetic model. Br J Anaesth 2003; 90: 183-8.

45 Motamed C, Devys J-M, Debaene B, Billard V. Influence of real-time Bayesian forecasting of pharmacokinetic parameters on the precision of a rocuronium target-controlled infusion. Eur $\mathrm{J}$ Clin Pharmacol 2012; 68: 1025-31.

46 Ma X-D, Yan J, Dai B-Z, Kong D-Q, Du S-Y, Li B-P. Comparative study: efficacy of closed-loop target controlled infusion of cisatracurium and other administration methods for spinal surgery of elderly patients. Eur Rev Med Pharmacol Sci 2017; 21: 606-11.

47 Kansanaho M, Olkkola KT. Performance assessment of an adaptive model-based feedback controller: comparison between atracurium, mivacurium, rocuronium and vecuronium. Int J Clin Monit Comput 1997; 13: 217-24.

48 Eleveld DJ, Proost JH, Wierda JM. Evaluation of a closed-loop muscle relaxation control system. Anesth Analg 2005; 101: 758-64.

49 Eriksson LI. Evidence-based practice and neuromuscular monitoring: it's time for routine quantitative assessment. Anesthesiology 2003; 98: 1037-9.

50 Vanacker BF, Vermeyen KM, Struys MM, Rietbergen H, Vandermeersch E, Saldien V, Kalmar AF, Prins ME. Reversal of rocuronium-induced neuromuscular block with the novel drug sugammadex is equally effective under maintenance anesthesia with propofol or sevoflurane. Anesth Analg 2007; 104: 563-8.

51 Ploeger BA, Smeets J, Strougo A, Drenth HJ, Ruigt G, Houwing N, Danhof M. Pharmacokineticpharmacodynamic model for the reversal of neuromuscular blockade by sugammadex.

Anesthesiology. 2009 Jan;110(1):95-105

52 Kleijn HJ, Zollinger DP, van den Heuvel MW, Kerbusch T. Population pharmacokineticpharmacodynamic analysis for sugammadex-mediated reversal of rocuronium-induced neuromuscular blockade. British journal of clinical pharmacology. 2011 Sep 1;72(3):415-33. 53 Proost JH, Schiere S, Eleveld DJ, Wierda JM. Simultaneous versus sequential pharmacokineticpharmacodynamic population analysis using an iterative two-stage Bayesian technique. Biopharmaceutics \& drug disposition. 2007 Nov 1;28(8):455-73.

54 Schmith VD, Fiedler-Kelly J, Phillips L, Grasela TH. Prospective use of population pharmacokinetics/pharmacodynamics in the development of cisatracurium. Pharmaceutical research. 1997 Jan 1;14(1):91-7. 
55 Liu J, Lu C, Zou Q, Wang S, Peng X. Altered pharmacodynamics and pharmacokinetics of cisatracurium in patients with severe mitral valve regurgitation during anaesthetic induction period. British journal of clinical pharmacology. 2017 Feb 1;83(2):363-9.

56 Tran TV, Fiset P, Varin F. Pharmacokinetics and pharmacodynamics of cisatracurium after a short infusion in patients under propofol anesthesia. Anesthesia \& Analgesia. $1998 \mathrm{Nov}$ 1;87(5):1158-63. 